\title{
Holdout in the Assembly of Complements: A Problem for Market Design
}

\author{
By Scott Duke Kominers And E. Glen WeyL*
}

The Colombian government's recent efforts to aggregate land for housing and infrastructure have run into holdout problems. Hundreds of distinct individual sellers must consent to assembly and many have demanded substantial, disproportionate shares of the total aggregation surplus. The Federal Communications Commission (FCC) faces comparable challenges in its efforts to repurpose spectrum, as profitable reallocation requires large contiguous spectrum blocks but spectrum ownership rights are fragmented among many sellers. Similar problems arise in a range of other contexts where a buyer attempts to aggregate complementary goods from many self-interested sellers.

While mechanisms that fully respect sellers' property rights ${ }^{1}$ cannot alleviate these holdout problems, traditional solutions, such as the use of coercive government powers of "eminent domain" to expropriate property, can encourage wasteful assemblies and undermine both owners' property rights and social standards of fairness. In Section I, we discuss the problems holdout creates for the efficient operation of markets and how previous approaches have used regulated coercion to address these challenges. Then, in Section II, we investigate when encouraging competition can partially or fully substitute for coercion, focusing particularly on questions of spectrum allocation. Finally, we con-

\footnotetext{
* Kominers: Becker Friedman Institute, University of Chicago, 1126 East 59th Street, Chicago, IL 60637 (skominers@uchicago.edu). Weyl: Department of Economics, University of Chicago, 1126 East 59th Street, Chicago, IL 60637 (weyl@uchicago.edu). The authors thank Jeff Ely, John Hatfield, Alisha Holland, Sonia Jaffe, Tom Nicholas, Greg Rosston, Perry Shapiro, and Michael Whinston for helpful comments. Kominers gratefully acknowledges the support of an NSF Graduate Research Fellowship, a Yahoo! Key Scientific Challenges Program Fellowship, and a Terence M. Considine Fellowship in Law and Economics funded by the John M. Olin Center at Harvard Law School. Additionally, both authors appreciate the support of the Harvard Real Estate Academic Initiative, and the excellent research assistance of Alison Lanski, Stephanie Lo, Balaji Narain and William Weingarten.

${ }^{1}$ Viz. mechanisms that are individually rational for sellers.
}

clude in Section III, with a number of open questions.

\section{Assembly of Perfect Complements}

When multiple sellers own perfectly complementary components of a good, each seller seeks a share of the surplus from the components' assembly, thereby driving up the price of the good and reducing profits. This holdout problem has been recognized in economics at least since the work of Cournot (1838). ${ }^{2}$ In fact, Bergstrom (1978) showed that if each seller names her own price, then the likelihood of assembling an aggregate good approaches 0 as the number of sellers of complementary components grows large.

\section{A. Examples}

Both governments and private developers face holdout when attempting to assemble and repurpose large plots of land. Many countries require that an individual or corporation seeking to obtain control of a public firms bid for all the firm's shares; this may induce shareholder holdout (Grossman and Hart, 1980). Investors face holdout in assembling pools of complementary patents for joint licensing. Holdout problems also arise in debt settlements and combinatorial auctions. $^{3}$

\section{B. Traditional Approaches}

One traditional solution to holdout is for the buyer to make take-it-or-leave-it offers to the individual sellers, with those offers being realized if and only if the sellers unanimously agree to accept them. ${ }^{4}$ This system incentivizes sellers to report their values truthfully, and fully respects

\footnotetext{
${ }^{2}$ This problem is often termed "anticommons."

${ }^{3}$ Heller (2008) surveys a number of other rich examples.

${ }^{4}$ This approach dates back at least to the work of Wicksell (1896); it was recently formalized and analyzed by Grossman et al. (2010).
} 
seller property rights. ${ }^{5}$ Unfortunately, it seems unlikely to mitigate holdout in practice unless the buyer has accurate estimates of the individual sellers' valuations.

EXAMPLE 1: Suppose there are 100 sellers of perfect complements and that a buyer seeking to assemble the complements makes take-it-orleave-it offers generous enough that she is confident that each seller will (independently) accept with probability .95 . Then the probability that she will manage the assembly is $(.95)^{100}<.01$.

As Example 1 illustrates, unanimous consent of many complementary sellers is unlikely even once value-shading incentives are eliminatedwith high probability, at least one genuinely stubborn holdout will undermine the assembly. This problem is not particular to the take-it-orleave-it offer mechanism. Mailath and Postelwaite (1990) showed that any private (voluntary and self-financing) mechanism ${ }^{6}$ must lead to the disappearance of all trade as the number of perfectly complementary sellers grows large. Thus, just as with public goods, any mechanism that permits assembly in large markets (with positive probability) requires some degree of coercion.

Unfortunately, unlike in the provision of public goods, assembly projects are often brought forward for the benefit of private parties. These agents may be better informed than public authorities about both their own private values for the assembled good and the potential sellers' individual values for their components. This undermines the efficiency of traditional coercive solutions, such as eminent domain. To the extent that a private project is likely to be valuable in the areas where sellers' private values are likely to be high, prospective buyers will exploit coercive power to adversely select proposals that are most harmful to sellers (Kaplow and Shavell, 1996). Thus, unless sellers are offered a means to veto assembly, coercive solutions to holdout may do more harm than good. As a result, most historical solutions to holdout have either given sellers some collective recourse against assembly or have attempted to limit the scope of coercion to cases of clear public value.

\footnotetext{
${ }^{5}$ Here, we disregard the possibility that the buyer may face a commitment problem.

${ }^{6}$ That is, a mechanism in which every seller has the right to opt out and no external subsidies are provided.
}

\section{Market Design}

Any successful mechanism for reducing holdout must strike a delicate balance. While full protection of property rights can preclude any possibility of efficient assembly, weakening sellers' property rights may encourage frivolous and exploitative assemblies. Effective design must also seek a fair distribution of costs and benefits among potential sellers, both for its own sake (as with public goods) and to avoid undermining incentives for investment (de Soto, 2003).

In other work (Kominers and Weyl, 2011), we advance an approach to reducing holdout while maintaining a second-best notion of property rights. In particular, we propose that profits from sale be divided among the sellers in accordance with their ex ante expected shares of the total value, with sellers provided a collective veto opportunity through an efficient decision mechanism. The division rule is partially coerciveindividual sellers cannot veto assembly-but nevertheless guarantees that each seller is paid according to an unbiased estimate of her value (based on all aggregate information available) if her property is taken. ${ }^{7}$

Unfortunately, implementing our approach requires a reliable, efficient collective decisionmaking procedure - and such a procedure may not be readily available. Robustly incentivecompatible collective decision-making procedures, like the Vickrey-Clarke-Groves mechanism, may be especially susceptible to collusion and other manipulations, and face problems of budget-imbalance (Ausubel and Milgrom, 2005). Implementing Bayesian incentivecompatible procedures, such as the expected externality mechanism of Arrow (1979) and d'Aspremont and Gérard-Varet (1979), requires both the planner and agents to have detailed information on the distribution of valuations. More traditional voting procedures-as were used in 18th century Britain for approving farm enclosures (Hoffman, 1988) - are straightforward for sellers but, like Bayesian incentivecompatible mechanisms, require distributional information for calibrating the voting thresh-

\footnotetext{
${ }^{7}$ Thus, under this rule, sellers are paid according to the "community consensus on the severity of the harm inflicted," which some legal scholars consider an appropriate standard of "just compensation" (Ellickson, 1973).
} 
old. ${ }^{8}$

\section{Combinatorial Holdout: Competition vs. Complementarity}

Not all components of an aggregate good need be perfectly complementary-there is often some competition between complementary sellers. Given the difficulty of designing holdoutreducing mechanisms, in this section we illustrate (through examples) how and when competition alone may mitigate holdout. Our examples provide stylized models of the FCC's allocation of electromagnetic spectrum, and thus illustrate some of the issues in the recent debates over "incentive auctions" for spectrum reassembly.

As in Example 1, we focus throughout on the case in which buyers make take-it-or-leave-it offers that are symmetric relative to the distribution of (potential) sellers' values, so that the buyer obtains each seller's consent with (common) independent probability $p$. This simple exercise does not represent the optimal mechanism selection but nevertheless may provide instructive intuitions for market design: If assembly is unlikely for any individual consent probability $p<1$, then all non-coercive mechanisms are likely to face challenges. Meanwhile, if assembly is likely for all $p>0$, as with competition in an auction, non-coercive mechanisms are likely to work well.

\section{A. Competition Within Clusters}

We assume that there are $k M^{2}$ components partitioned into $k M$ clusters, each of which contains $M$ distinct sellers. We first suppose that competition may exist within clusters, that is, a buyer might require one component within each cluster, but is indifferent as to units within clusters. This roughly corresponds to the situation arising in many classic spectrum auctions, where a single buyer can succeed only if she is able to establish a national footprint, but that buyer is indifferent as to the spectrum bands received in individual markets. ${ }^{9}$

\footnotetext{
${ }^{8}$ Because voting does not incorporate cardinal information on valuations, approval of assembly through a voting mechanism corresponds to among-seller efficiency only if the planner sets the threshold for voting equal to the quantile of the distribution of values corresponding to the distribution's (empirical) mean (Ledyard and Palfrey, 2002).

${ }^{9}$ Similar within-cluster competition arises in the purchase of land for transportation routes, as the possibility of local rerouting
}

EXAMPLE 2: We suppose that a (prospective) buyer must acquire at least one component from each of $k M$ clusters, and that the buyer makes take-it-or-leave-it offers so as to obtain each owner's consent with probability $p$. Then, the probability of obtaining at least one component from each cluster is $1-(1-p)^{M}$, and the probability of succeeding in the overall assembly is

$$
\left(1-(1-p)^{M}\right)^{k M}
$$

Thus, if we let $\hat{p} \equiv 1-p$, as $M$ grows large, the logarithm of the probability that assembly succeeds is

$$
\begin{aligned}
& k \cdot\left(\lim _{M \rightarrow \infty} M \cdot \log \left(1-\hat{p}^{M}\right)\right) \\
& =k \cdot\left(\lim _{M \rightarrow \infty} \frac{\log \left(1-\hat{p}^{M}\right)}{\frac{1}{M}}\right) \\
& =-k \cdot \log (\hat{p}) \cdot\left(\lim _{M \rightarrow \infty} \frac{M^{2}}{\hat{p}^{-M}-1}\right) \\
& =2 k \cdot\left(\lim _{M \rightarrow \infty} \frac{M}{\hat{p}^{-M}}\right) \\
& =0,
\end{aligned}
$$

where the second and third equalities follow from L'Hôpital's Rule, and the last equality follows follows because $\hat{p}^{M}$ is exponential in $M$, $0<\hat{p}<1$, and $M$ is linear.

We therefore see that the probability of successful assembly approaches $e^{0}=1$.

Thus, competition within clusters creates a competitive environment for assembly in large markets. This observation may help explain why holdout problems have not been considered severe in traditional spectrum allocation contexts.

\section{B. Competition Across Clusters}

As in Section II.A, we assume that $k M$ clusters are available, and that each cluster contains $M$ components. Now, however, we consider competition across clusters: prospective buyers require all of the components within a cluster, but are indifferent across clusters. This structure approximates that present in the FCC's recent spectrum reallocation efforts, where large, contiguous spectrum blocks are needed but many

allows competition among local land-owners. 
such blocks are available in each region. ${ }^{10}$

EXAMPLE 3: Suppose that a (prospective) buyer must assemble all of the components within any one of the $k M$ clusters, and suppose again that the buyer makes take-it-or-leave-it offers so as to obtain each owner's consent with independent probability $p$.

The probability of assembling any given set of $M$ components is $p^{M}$, so the probability that no cluster is completely assembled is

$$
\left(1-p^{M}\right)^{k M}
$$

By the reasoning used in Example 2, we see that the probability of failure now approaches 1 .

At least under the simple take-it-or-leaveit offer procedure, competition across clusters of complementary sellers does not resolve the holdout problem if the number of competing clusters grows in proportion to the number of sellers in each cluster. This may help explain the widespread concern about holdout in the FCC's proposed spectrum reassembly program.

\section{Repacking}

A popular coercive proposal for reducing reducing holdout in spectrum reassembly is "repacking," under which the FCC could reassign broadcast frequencies so that any set of $M$ assembled frequencies could be converted into an $M$-band contiguous spectrum block (Cramton, 2011; Rosston, 2012). We briefly consider the extent to which such a policy is likely to alleviate holdout. ${ }^{11}$

The setting of Section II.B corresponds to the case in which a region's spectrum is partitioned among $(k+1) M-1$ distinct broadcasters and the FCC must assemble $M$ contiguous bands, if we ignore overlap between clusters. ${ }^{12}$ In the

\footnotetext{
${ }^{10}$ Across-cluster competition also arises in the assembly of land for a project, such as a housing project or shopping mall, for which many potential sites are possible but a given site must include several contiguous plots.

${ }^{11}$ Note that we assess neither the cost nor fairness of repacking - such analyses are outside the scope of this article but important for future work.

${ }^{12} \mathrm{~A}$ linearly-ordered set of $N$ bands has exactly $N-M+1$ subsets containing $M$ contiguous bands. Thus, $(k+1) M-1$ bands give rise to
}

$$
((k+1) M-1)-M+1=k M
$$

distinct clusters. presence of repacking, the FCC must only assemble some $M$ of the $(k+1) M-1$ bands. ${ }^{13}$

EXAMPLE 4: Suppose a buyer must assemble $M$ of $(k+1) M-1$ components and that, as above, the buyer purchases each component with independent probability $p$. By the law of large numbers, when $M$ is large, the buyer will successfully purchase (approximately)

$$
p(k+1) M
$$

components. Thus for large $M$, assembly succeeds if and only if $p \geq \frac{1}{k+1}$.

With repacking, the buyer must buy from each seller with substantial probability in order for assembly to succeed. However, unlike when competition is only across clusters, some probability of purchase $p$ strictly between 0 and 1 will lead to successful assembly-even in large markets. Thus we may see that repacking solves the holdout problem, but does not create perfect competition even in large markets.

\section{Conclusion}

It is possible that a sophisticated mechanism, perhaps resembling an auction or exploiting overlaps in cluster membership, would make competition across clusters more powerful, even in the absence of repacking. In any case, determining efficient and practical mechanisms for combinatorial holdout settings is an important open design problem. Additionally, work to understand more broadly which combinatorial settings allow trade without coercion will be useful for applications. In combinatorial holdout settings where, as in the case of perfect complements, any incentive-compatible mechanism is unlikely to yield reasonable volumes of trade, traditional combinatorial auction approaches may be insufficient and explicitly coercive collective choice rules may be required.

More effective procedures for collective decision-making are needed for cases in which coercion is necessary. Such mechanisms might, for example, make use of vote-buying systems (e.g., Casella et al. (2010)) or new approaches

\footnotetext{
${ }^{13}$ Repacking is also possible in land assembly problems for which either contiguity is not crucial (as in the development of a company town) or relocation of land-owners is relatively inexpensive.
} 
to incentive compatibility in large markets (e.g., Azevedo and Budish (2011)). The necessity of coercion for holdout reduction also leads to questions about appropriate notions of fairness and their relationships to sellers' investment incentives. Effective alternatives to a community veto as a means of avoiding frivolous assembly would also be valuable.

\section{REFERENCES}

Arrow, Kenneth J., "The Property Rights Doctrine and Demand Revelation under Incomplete Information," in Michael Boskin, ed., Economics and Human Welfare, New York: Academic Press, 1979, pp. 23-39.

Ausubel, Lawrence M. and Paul Milgrom, "The Lovely but Lonely Vickery Auction," in Peter Cramton, Richard Steinberg, and Yoav Shoham, eds., Combinatorial Auctions, Cambridge, MA: MIT Press, 2005, pp. 17-40.

Azevedo, Eduardo M. and Eric Budish, "Strategyproofness in the Large as a Desideratum for Market Design," 2011. Mimeo, Booth School of Business, University of Chicago.

Bergstrom, Ted, "Cournot Equilibrium in Factor Markets," 1978. Mimeo, University of California Santa Barbara.

Casella, Alessandra, Aniol Llorente-Saguer, and Thomas R. Palfrey, "Competitive Equilibrium in Markets for Votes," 2010. NBER Working Paper No. 16315.

Cournot, A. Augustin, Recherches sur les Principes Mathematiques de la Theorie des Richess, Paris, 1838.

Cramton, Peter, "Incentive Auctions and Spectrum Policy," 2011. Testimony Before the United States House Committee on Energy and Commerce.

d'Aspremont, Claude and Louis-André Gérard-Varet, "Incentives and Incomplete Information," Journal of Public Economics, 1979, 11 (1), 25-45.

de Soto, Hernando, The Mystery of Capital: Why Capitalism Triumphs in the West and Fails Everywhere Else, New York: Basic Books, 2003.
Ellickson, Robert C., "Alternatives to Zoning: Covenants, Nuisance Rules, and Fines as Land Use Controls,' University of Chicago Law Review, 1973, 40 (4), 683-781.

Grossman, Sanford J. and Oliver D. Hart, "Takeover Bids, the Free-Rider Problem, and the Theory of the Corporation," Bell Journal of Economics, 1980, 11 (1), 42-64.

Grossman, Zachary, Jonathan Pincus, and Perry Shapiro, "A Second-Best Mechanism for Land Assembly,” 2010. Mimeo University of California Santa Barbara.

Heller, Michael, The Gridlock Economy: How Too Much Ownership Wrecks Markets, Stops Innovation and Cost Lives, Philadelphia, PA: Basic Books, 2008.

Hoffman, Philip T., "Institutions and Agriculture in Old Regime France," Politics and Society, 1988, 16 (2-3), 241-264.

Kaplow, Louis and Steven Shavell, "Property Rules versus Liability Rules: An Economic Analysis," Harvard Law Review, 1996, 109 (4), 713-790.

Kominers, Scott Duke and E. Glen Weyl, "Concordance among Holdouts," 2011. Mimeo, University of Chicago.

Ledyard, John O. and Thomas R. Palfrey, "The Approximation of Efficient Public Good Mechanisms by Simple Voting Schemes," Journal of Public Economics, 2002, 83 (2), 153-171.

Mailath, George J. and Andrew Postelwaite, "Asymmetric Information Bargaining Problems with Many Agents," Review of Economic Studies, 1990, 57 (3), 351-367.

Rosston, Gregory, "Incentive Auctions," Communications of the ACM, 2012, 55 (2).

Wicksell, Knut, Finanztheoretische Untersuchungen: Nebst Darstellung und Kritik des Steuerwesens Schwedens, Jena: Gustav Fischer, 1896. 